\title{
Information acquisition and financial contagion
}

\author{
Augusto Hasman ${ }^{1}$, Margarita Samartín * $\bar{\equiv}$ \\ Business Department, Universidad Carlos III de Madrid, Spain
}

\begin{abstract}
This paper incorporates costly voluntary acquisition of information à la Nikitin and Smith (2007) [Nikitin, M., Smith, R.T., 2007. Information acquisition, coordination, and fundamentals in a financial crisis. Journal of Banking and Finance, in press, doi:10.1016/ j.jbankfin.2007.04.031], in a framework similar to Allen and Gale (2000) [Allen, F., Gale, D., 2000. Financial contagion. Journal of Political Economy 108, 133 ], without relying on any unexpected shock to model contagion. In this framework, contagion and financial crises are the result of information gathering by depositors, weak fundamentals and an incomplete market structure of banks. It also shows how financial systems entering a recession can affect others with apparently stronger economic conditions (contagion). Finally, this is the first paper to investigate the effectiveness of the Contingent Credit Line procedures, introduced by the IMF at the end of the nineties, as a mechanism to prevent the propagation of crises.
\end{abstract}

JEL classification: G21; D82

Keywords: Central Bank; Contingent Credit Line; Financial Contagion; Fundamentals; Verification equilibrium

"We are giving countries a greater financial incentive to adopt crisis resistant policies by offering those that do Contingent Credit Lines to protect them from contagion effects"

Stanley Fisher, First Deputy Managing Director of the IMF (1994 2001), Policy Issues Forum, Washington DC, April 28, 2001.

\section{Introduction}

Financial crises are costly and frequent events. During the last twenty five years, more than two thirds of the Inter

\footnotetext{
* Corresponding author. Tel.: +34 916249647; fax: +34 916249607.

E-mail addresses: ahasman@emp.uc3m.es (A. Hasman), samartin@ emp.uc3m.es (M. Samartín).

${ }^{1}$ Tel.: +34 916249772; fax: +34916249607.
}

national Monetary Fund (IMF) member countries have suffered some kind of financial troubles (see Lindgren et al., 1996; Beim and Calomiris, 2001).

These financial crises reflect the fact that the financial system, and especially the banking sector, not only can amplify and transfer problems originated in other sectors of the economy, but can also be a main driver of such crises (for example, the financial crises of Mexico 1994, Korea 1997 and Turkey 2000 had the banking sector weaknesses at the core). Financial institutions are often linked to each other through direct portfolio or capital connections that are desirable ex ante, but during a crisis the failure of one institution can have direct negative effects on the other institutions linked to it (see Rochet and Tirole, 1996; Agh ion et al., 2000; Freixas and Parigi, 1998; Freixas et al., 2000; Allen and Gale, 2000).

This paper provides a novel view on the interplay of sun spots and fundamentals in the development of financial cri ses. In particular, it does not rely on any unexpected shock to model contagion. In this framework, contagion and 
financial crises are the result of information gathering by depositors, weak fundamentals and an incomplete market structure of banks. It also shows how financial systems entering a recession can affect others with apparently stron ger economic conditions (contagion). Finally, this is the first paper to investigate the effectiveness of the Contingent Credit Line procedures, introduced by the IMF at the end of the nineties, as a mechanism to prevent the propagation of crises.

We model a four region economy, where the representa tive bank of each region has access to an illiquid long term investment project that allows depositors to increase their expected welfare. Half of the banks are going to receive a low return on their investment and will be called "bad banks", the other half will receive a high return on their projects and will be called "good banks". Additionally, banks will maintain interbank linkages to reduce aggregate uncertainty. Nevertheless, full linkages among banks are not always possible and sometimes unstable structures are set and contagion may occur.

We present three different banking market structures. First, a market where all banks maintain interbank link ages (complete market structure). Second, the neighboring case, where banks are just financially connected to their neighbors but indirectly to all the others. Finally, the island case, where each bank keeps linkages with only one bank. We will show that in the complete market structure the first best allocation is achieved. In the neighboring case, differ ent equilibria are possible: a verification equilibrium with partial runs (with and without contagion), a verification equilibrium with total runs, a full run equilibrium and a no run equilibrium.

In the verification equilibria depositors gather informa tion and penalize inefficient banks. In one of those equilib ria, bank runs only take place in bad banks (partial bank runs), although other banks might be affected as well (con tagion). In the second equilibrium, there is a global with drawal from the banking system in a contagious fashion. There is also a full run equilibrium, where depositors do not gather information but withdraw in a pure panic way, and one, characterized by no runs and no information gathering. In the island case three different equilibria are possible: the verification equilibrium, the full run equilib rium, and the no run equilibrium. In the verification equi librium, bank runs are partial and there is no contagion. Nevertheless, the expected utility is higher in the neighbor ing case than in the island case.

The equilibria with crises of the model are fundamen tals based and panic based at the same time. Bank runs are related to fundamentals, although this does not mean that bad fundamentals per se cause the run. Investors' coordination on a particular equilibrium is triggered by a self fulfilling prophecy. When the system is at rest, individ uals do not find it optimal to gather information and so the model explains why there are periods in which individuals do not modify their expectations on banks. However, if for any reason they decide to invest in information gathering they would penalize those states of nature in which banks establish inefficient links. This would cause the liquidation of bad projects, but it might also generate contagion and financial crises when financial linkages are very inaccurate.

Following, we define the role for a Central Bank as a market completer. The mechanism we analyze is the one similar to the Contingent Credit Line (CCL) of the IMF. The idea of the CCL is to provide a precautionary line of defense for members with sound policies, who are not at risk of an external payments crisis of their own making, but vulnerable to contagion effects from capital account crisis in other countries. We show that the CCL is a pow erful mechanism to prevent financial crises in environments characterized by incomplete markets and distrustful depositors.

The lack of strong evidence of contagious bank failures in the periods in which the Central Bank played an active role as a lender of last resort does not disprove the possibility of financial contagion through the banking system. The recent episode (September 2007) of depositors queuing at the Northern Rock bank in the UK trying to withdraw their money, has shown that it is possible to have distrustful depositors even in the presence of deposit insurance, author ities defending the solvency of the institution and a healthy real economy. Additionally, banks in England and other countries in Europe ${ }^{2}$ attempting to get more liquidity is a warning of the possibility of contagion. Our model is an attempt to give some insights into this possibility, and in explaining that a healthy interbank market is crucial in pre venting contagious bank failures. It is obvious that more work on anticipating and preventing such crises is needed, and our paper is an attempt to go in such direction.

This paper goes in line with Allen and Gale (2000), Saez and Shi (2004), Leitner (2005) and Castiglionesi and Bru sco (2007) in the sense that banks maintain interbank link ages but with the purpose to insure against negatively correlated technological shocks (fundamentals). The pro posed model incorporates voluntary costly acquisition of information à la Nikitin and Smith (2007), but in our case individuals are not allowed to maintain deposits in different banks, although this is done by banks themselves. This allows us to explain contagion.

As in Allen and Gale (2000), we model contagion as an equilibrium phenomenon. However, we do not require an unexpected event to model contagion. Banks maintain interbank linkages to insure against technological shocks and this makes them fragile against information acquisition by depositors. In such context, the "incompleteness" of the interbank claims will determine the possibility of contagion.

Saez and Shi (2004) introduce the concept of a liquidity pool, a claim structure where banks are indirectly con nected, which guarantees liquidity in the presence of an insolvent bank and impedes contagion. In our case the

\footnotetext{
${ }^{2}$ For example, the Deutsche bank had bought $3.56 \%$ of Northern Rock, consequently, the values of its shares were also affected.
} 
Central Bank provides an efficient solution to overcome financial contagion. As in Castiglionesi (2007), the Central Bank plays the role of a market completer but when the problems are due to fundamentals and not to liquidity ones. Therefore, the results of the present paper indicate that those institutions should be free of intervention by local governments since their objective is to work as a "market completer" or global insurer avoiding the usual political restrictions to capital mobility. Such institutions reallocate resources from developed to underdeveloped economies allowing the system to achieve the first best allocation.

The work by Leitner (2005), introduced the threat of contagion as part of the optimal network design. The idea is that when agents are not linked to one another, agents who have high endowments have no incentive ex post to help out those who have low endowments. Thus, some positive net present value investments do not take place. On the other hand, when agents are linked to one another, agents with high endowments are willing to bail out those with low endowments, since failure to do so leads all projects to fail by contagion. On the contrary, in the present paper, the linkages appear because banks cannot anticipate the success of their projects, and there fore the possibility of contagion is a cost that banks have to assume.

The seminal contribution by Castiglionesi and Brusco (2007) provides a model where different regions are subject to different levels of moral hazard, and have negatively correlated liquidity needs. Integrated financial markets increase expected social welfare, but only at the cost of greater financial instability. As a consequence, and con trary to Allen and Gale's finding, contagion is greater the more interconnected banks are. They conclude that banks establish links and accept the risk of contagion, only when the risk is not too high. In this respect, it is close to our results for incomplete markets. We find that the more incomplete the banking structure is, read the island case, the less vulnerable to contagion it is. Never theless, depositors prefer the neighboring case to the island case.

The rest of the paper is organized as follows: the basic model is presented in Section 2. Section 3 describes the social optimal allocation. Section 4, introduces financial intermediaries (banks), and analyzes different market struc tures and their respective equilibria. Sections 5 shows how a Central Bank provides an efficient solution to overcome financial contagion. Finally, Section 6 presents a numerical example and Section 7 concludes.

\section{The model}

We consider a three date $(t=0,1,2)$ economy and one single good. There are two types of assets: A liquid asset that takes one unit of the good at date $t$ and converts it into one unit of the good at date $t+1$ (storage). An illiquid asset that takes one unit of the good at date 0 and trans forms it into $R^{H}$ or $R^{L}$ units of the good at date 2 depending on the state of nature. It is assumed that $0 \leqslant R^{L}<1<R^{H}$ and that the expected return $\left(\bar{R}=\frac{1}{2} R^{L}+\frac{1}{2} R^{H}\right)$ is greater than one. If the illiquid technology is liquidated prema turely at $t=1$, we obtain $r$, with $0 \leqslant r<1$.

There are four regions in this economy. Each region consists of a continuum of ex ante identical consumers depositors with an endowment of one unit of the consump tion good at $t=0$. They are subject at $t=1$ to a privately observed uninsurable risk of being of either of two types. Type 1 (or impatient) agents derive only utility from con sumption in period one and type 2 (or patient) agents derive only utility from consumption in period 2 . In addi tion, type 2 agents can privately store the good from $t=1$ to $t=2$. Their utility function is as follows:

$$
U\left(c_{1}, c_{2}\right)= \begin{cases}u\left(c_{1}\right) & \text { with probability } \gamma(\text { Type } 1), \\ u\left(c_{2}\right) & \text { with probability }(1 \quad \gamma) \text { (Type } 2),\end{cases}
$$

where the utility function $u($.$) is defined over non negative$ levels of consumption, is strictly increasing, strictly concave, twice continuously differentiable, and satisfies Inada conditions. There is no aggregate uncertainty and so the probability $\gamma$ represents the fraction of early consum ers in the economy. Consumer's type is his private information.

There is also a continuum of identical banks in each region, or a representative bank in each region. A bank is a financial institution which invests in the technology on behalf of consumers and provides them with consumption at $t=1$ or $t=2$. Each consumer deposits his endowment in the bank at $t=0$, and in exchange he receives a demand deposit contract. Competition among banks forces them to offer a contract that maximizes the expected utility of the representative consumer. This contract pays a fixed amount at each date, and in the event that this is not pos sible all available funds will be divided pro rata in propor tion to claims (as in Allen and Gale (1998), we do not assume a sequential service constraint). In particular, the demand deposit contract gives the depositor the right to withdraw either $c_{1}$ at $t=1$ or $c_{2}(R)$ at $t=2$. The second period random return reflects the fact that having invested in a random technology, the bank may not be able to make its promised payment at date 2 . In this sense the only risk the depositors bear is that they will not be repaid their money in the situation in which it is physically impossible to repay them.

It is also assumed that banks in half of the regions will obtain a high return on their investment project (expansion banks, from now on good banks), and the other half a low one (recession banks, from now on bad banks). Neither bankers nor depositors know the type of their own banks nor that of the other ones. Nevertheless, they know the dis tribution of shocks in the whole economy. The information is revealed to consumers depositors at $t=2$, although they can obtain information at $t=1$ at a cost of $\varepsilon$. This 
information cost can be understood as a monitoring cost. Although information might be perfect and free, depositors need time and other resources to process it. ${ }^{3}$

Notice that if we consider all banks as a single one there is no aggregate uncertainty concerning technology shocks, since $\bar{R}=\frac{1}{2} R^{L}+\frac{1}{2} R^{H}$. Finally, it is assumed that depositors cannot deposit in banks in more than one region.

\section{Social optimum}

The problem of the social planner is to maximize the expected welfare of a representative consumer. We will focus on the range of parameters under which the social planner should never interrupt illiquid technology investment at $t=1^{4}$ and even inefficient projects should be completed and resources on verification should not be spent. The social planner should use storage to provide for consumption of impatient agents. The planner maximizes:

$$
\begin{array}{cl}
\underset{\left\{x, y, c_{1}, c_{2}\right\}}{\operatorname{Max}} & \gamma u\left(c_{1}\right)+(1 \quad \gamma) u\left(c_{2}\right), \\
\text { subject to } & x+y \leqslant 1 ; \\
& \gamma c_{1} \leqslant y ; \\
& (1 \quad \gamma) c_{2} \leqslant \bar{R} x ; \\
& x \geqslant 0 ; \quad y \geqslant 0 ; \quad c_{1} \geqslant 0 ; \quad c_{2} \geqslant 0 ;
\end{array}
$$

where $y$ is the amount invested in storage, $x$ is the amount invested in the illiquid technology, $c_{1}$ is the con sumption of impatient consumers and $c_{2}$ the consumption of patient ones. Eq. (2) is the expected utility to be maxi mized. Eq. (3) is the date 0 constraint which states that all the resources should be used for storage or investment and Eq. (4) the first period one. It states that the amount of storage should be enough to provide for consumption of type 1 consumers. Similarly, Eq. (5) shows that the con sumption of type 2 consumers comes from the illiquid technology.

Optimality requires that the feasibility constraints are satisfied with equality, so we can write the problem as

$$
\operatorname{Max}_{y \in[0,1]} \gamma u\left(\frac{y}{\gamma}\right)+\left(\begin{array}{ll}
1 & \gamma
\end{array}\right) u\left(\frac{1}{1} \frac{y}{1} \bar{R}\right) \text {. }
$$

Since $u(\cdot)$ is strictly concave and satisfies the Inada condi tions, the solution to problem (7) is unique and interior. The optimal value $y^{*} \epsilon(0,1)$ is obtained from the first order condition

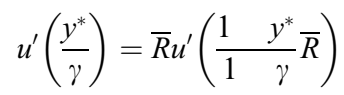

\footnotetext{
${ }^{3}$ See Nikitin and Smith (2007) for a discussion of this assumption.

${ }^{4}$ Verification is never socially optimal for values of $\varepsilon$, such that,

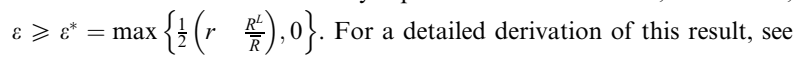
Nikitin and Smith (2007).
}

and once $y^{*}$ has been determined by Eq. (8) we can use the feasibility constraints to determine the other variables:

$c_{1}^{*}=\frac{y^{*}}{\gamma}, \quad c_{2}^{*}=\frac{\left(\begin{array}{ll}1 & y^{*}\end{array}\right)}{1} \bar{R}, \quad x^{*}=1 \quad y^{*}$.

Notice that (8) and (9) imply that $u^{\prime}\left(c_{1}^{*}\right)=\bar{R} u^{\prime}\left(c_{2}^{*}\right)$, which in turn implies $u^{\prime}\left(c_{1}^{*}\right)>u^{\prime}\left(c_{2}^{*}\right)$ and $c_{2}^{*}>c_{1}^{*}$. Thus, the first best allocation automatically satisfies the incentive constraint $c_{2} \geqslant c_{1}$, that is late consumers have no incentive to behave as early consumers. We will call $\Psi^{*} \equiv\left(y^{*}, x^{*}, c_{1}^{*}, c_{2}^{*}\right)$ the first best allocation, and $U^{*}$ the expected utility achieved under the first best allocation.

\section{Decentralized economy with banks}

Decentralization of the social optimal allocation can be achieved in the same way as in Allen and Gale (2000). Each bank issues demand deposits contracts. These deposits pay $c_{1}^{*}=\frac{y^{*}}{\gamma}$ if withdrawn in the first period, provided that the bank is solvent. In the second period all remaining assets are liquidated and allocated among deposit holders on a pro rata basis.

Each bank stores $y^{*}$ share of the period 0 deposit, and invests the rest in the illiquid technology. The amount of storage technology should be enough to just satisfy the liquidity needs of impatient agents. Additionally, banks are going to establish linkages ex ante, in order to insure against the technology shock. Let $z_{i j}$ be defined as the loan that bank $j$ receives from bank $i$ (by assumption $z_{i j}=z_{j i}$ ). Given that agents are risk averse, and that the bank type may be revealed only in period 1, it is optimal that bank $i$ spreads interbank loans for an amount of $z_{i}=\left[\frac{n}{n+1}\right]=$ $\sum_{j 1, j / i}^{n+1} z_{i j}$ across the banking system (where $n$ is the number of links each bank has). This interbank loans pays $z_{i j} R^{H} x$ if kept until $t=2$, when the bank is of a good type, and $z_{i j} R^{L} x$ when the bank is of a bad type. ${ }^{5}$ If liquidated at $t=1$, it will pay the same as other deposits withdrawn in the first period $\left(z_{i j} c_{1}\right)$. Recall that the interbank loans are compensated simultaneously between banks, so if bank 1 decides to cancel its interbank loan at $t=1$, it will also have to pay back its obligation with the other banks in that period.

With four banks there are three types of financial link ages that are symmetrical: (1) the full linked case (complete market structure), (2) the neighboring case, and (3) the island case (the last two cases are examples of incomplete market structures). ${ }^{6} \mathrm{We}$ assume that the structure of the banking system is known at the very beginning but not the type of each bank nor that of the depositor.

\footnotetext{
${ }^{5}$ This structure of interbank loan payments facilitates savings in monitoring costs while profiting from diversification. It may also be interpreted as banks' shares in other banks in the system.

${ }^{6}$ We use symmetrical allocations for simplicity of exposition. However, similar results can be obtained with non-symmetrical linkages.
} 


\subsection{Complete market structure}

In the complete market structure (full linked case), each bank is linked to three other banks and therefore there is only one possible state of nature which is represented in Fig. 1.

From now on, $G_{1}$ and $G_{4}$ are going to be the good banks and $B_{2}$ and $B_{3}$ the bad banks. A number 1 in the matrix means that there is a linkage between those banks. In this case, $z_{i}=\frac{3}{4}$ and $z_{i j}=\frac{1}{4}$. In the presence of full linkages among banks, the first best equilibrium is achievable.

The demand deposit contract is obtained as a solution to the following problem:

$$
\begin{aligned}
& \operatorname{Max}_{\left\{x, y, c_{1}, c_{2}\right\}} \gamma u\left(c_{1}\right)+(1 \quad \gamma)\left[\frac{1}{2} u\left(c_{2}^{B}\right)+\frac{1}{2} u\left(c_{2}^{G}\right)\right], \\
& \text { subject to } x+y+z_{j} \quad z_{i} \leqslant 1 \text {; } \\
& \gamma c_{1} \leqslant y \\
& \left(\begin{array}{ll}
1 & \gamma
\end{array}\right) c_{2}^{B} \leqslant\left[\begin{array}{ll}
R^{L}(1 & z_{j}
\end{array}\right)+R^{L} z_{i j} \\
& \left.+R^{H} z_{i j}+R^{H} z_{i j}\right] x \text {; } \\
& \left(\begin{array}{ll}
1 & \gamma
\end{array}\right) c_{2}^{G} \leqslant\left[\begin{array}{ll}
R^{H}(1 & z_{j}
\end{array}\right)+R^{L} z_{i j} \\
& \left.+R^{L} z_{i j}+R^{H} z_{i j}\right] x \text {; } \\
& \frac{1}{2} u\left(c_{2}^{B}\right)+\frac{1}{2} u\left(c_{2}^{G}\right) \geqslant u\left(c_{1}\right) ; \\
& x \geqslant 0 ; \quad y \geqslant 0 ; \quad c_{1} \geqslant 0 ; \quad c_{2}^{B} \geqslant 0 ; \\
& c_{2}^{G} \geqslant 0 ; \quad z_{i}=z_{j}=\sum_{j}^{4} z_{i j / i} \text {; }
\end{aligned}
$$

where $c_{2}^{G}$ represents second period consumption in a good type bank and $c_{2}^{B}$ second period consumption in a bad type one. $z_{j}$ are total interbank loans received from other banks in the system and obviously $z_{j}=z_{i}=\sum_{j 1, j / i}^{4} z_{i j}$. Eq. (10) is the expected utility to be maximized. Eq. (11) is the period 0 constraint and Eq. (12) the first period one. Eqs. (13) and (14) correspond to the second period constrains, in the case of a bad bank and a good bank, respectively.

Given that each bank has an obligation equal to $z_{j} \widetilde{R}_{i} x$ with the rest of the system and at the same time has the right to receive $z_{i} \widetilde{R}_{j} x$ from the other banks; the resources available in the second period are given by the return of the projects minus the obligations with the system plus the right to receive from other banks: $\left[\begin{array}{ll}\widetilde{R}_{i} & z_{j} \widetilde{R}_{i}+z_{i} \widetilde{R}_{j}\end{array}\right] x$, where $\widetilde{R}_{i}$ is the expected return from our technology, and $\widetilde{R}_{j}$ is the expected return from our neighbors. Finally, Eq. (15) is the incentive compatibility constraint that guaran tees that type 2 depositors do not have incentives to imitate type 1 depositors.

It is straightforward to see that $c_{2}^{B}=c_{2}^{G}=c_{2}$ and $\left[R^{L}\left(1 \quad z_{j}\right)+R^{L} z_{i j}+R^{H} z_{i j}+R^{H} z_{i j}\right]=\bar{R}$; and therefore we have the same problem as in the social optimum given by Eqs. (2) (9). Since $c_{2}^{*}>c_{1}^{*}$, each agent has incentives to respect his type, and the social optimal allocation is attained. It is never optimal for consumers to spend resources in obtaining information about the type of the bank in the first period. This result is summarized in the following proposition.

Proposition 1. The first best allocation $\Psi^{*}$ is attainable in a complete market structure.

\subsection{The neighboring case}

In the neighboring case, banks are financially connected to two other banks in the system forming a close group. Given political, geographical and/or historical reasons, some regions like $\mathrm{A}$ and $\mathrm{C}$ or $\mathrm{B}$ and $\mathrm{D}$ in Fig. 2 are not directly connected although they are indirectly connected through their neighbors.

Bankers and consumers depositors know this informa tion from the very beginning, although they do not know in which type of bank they are nor the type of their neigh bor banks (they just know the structure of the game). Nev ertheless, depositors can obtain this information at $t=1$ at a cost of $\varepsilon$.

We have three possible states of nature: One case where a good bank is linked to two bad ones or a bad bank con nected to two good ones, Fig. 3a, and two cases where a good bank is connected to one good bank and one bad one, Fig. $3 \mathrm{~b}$ and c. All states are going to be equally prob able, and are represented in Fig. 3.

However, those three states of nature can be separated into two: that of Fig. 3a with probability $\frac{1}{3}$ and those of Fig. $3 \mathrm{~b}$ and $\mathrm{c}$ with probability $\frac{2}{3}$. In the neighboring case, each bank will maintain total interbank loans of $z_{i}=\frac{2}{3}$ and so $z_{i j}=\frac{1}{3}$. Now, consumers depositors are going to solve the following problem:

$\begin{array}{ccccc} & G_{1} & B_{2} & B_{3} & G_{4} \\ G_{1} & 0 & 1 & 1 & 1 \\ B_{2} & 1 & 0 & 1 & 1 \\ B_{3} & 1 & 1 & 0 & 1 \\ G_{4} & 1 & 1 & 1 & 0\end{array}$

Fig. 1. Complete market structure.

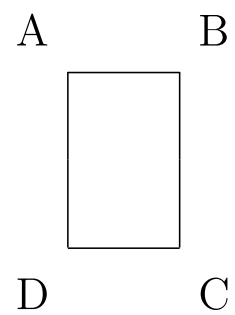

Fig. 2. The neighboring case. 


$\begin{array}{ccccccccccccccc} & G_{1} & B_{2} & B_{3} & G_{4} & & G_{1} & B_{2} & B_{3} & G_{4} & & G_{1} & B_{2} & B_{3} & G_{4} \\ G_{1} & 0 & 1 & 1 & 0 & G_{1} & 0 & 1 & 0 & 1 & G_{1} & 0 & 0 & 1 & 1 \\ B_{2} & 1 & 0 & 0 & 1 & B_{2} & 1 & 0 & 1 & 0 & B_{2} & 0 & 0 & 1 & 1 \\ B_{3} & 1 & 0 & 0 & 1 & B_{3} & 0 & 1 & 0 & 1 & B_{3} & 1 & 1 & 0 & 0 \\ G_{4} & 0 & 1 & 1 & 0 & G_{4} & 1 & 0 & 1 & 0 & G_{4} & 1 & 1 & 0 & 0\end{array}$

(a) State I

(b) State II

(c) State III

Fig. 3. States of nature in the neighboring case.

$$
\begin{aligned}
& \operatorname{Max}_{\left\{x, y, c_{1 N},\left\{c_{2 i}^{t} i_{i=L, H}^{t=1,2}\right\}\right.} \gamma u\left(c_{1 N}\right)+(1 \quad \gamma)\left\{\frac{1}{2}\left[\frac{1}{3} u\left(c_{2 L}^{1}\right)+\frac{2}{3} u\left(c_{2 L}^{2}\right)\right]\right. \\
& \left.+\frac{1}{2}\left[\frac{1}{3} u\left(c_{2 H}^{1}\right)+\frac{2}{3} u\left(c_{2 H}^{2}\right)\right]\right\} \\
& \text { subject to } x+y \quad z_{i}+z_{j} \leqslant 1 \text {; } \\
& \gamma c_{1 N} \leqslant y \\
& \left.\left(\begin{array}{ll}
1 & \gamma
\end{array}\right) c_{2 L}^{2} \leqslant\left[\begin{array}{ll}
R^{L}(1 & z_{j}
\end{array}\right)+R^{H} z_{i j}+R^{L} z_{i j}\right] x \\
& =\left[\frac{2}{3} R^{L}+\frac{1}{3} R^{H}\right] x \\
& \left(\begin{array}{ll}
1 & \gamma
\end{array}\right) c_{2 L}^{1} \leqslant\left[R^{L}\left(1 \quad z_{j}\right)+R^{H} z_{i j}+R^{H} z_{i j}\right] x \\
& =\left[\frac{1}{3} R^{L}+\frac{2}{3} R^{H}\right] x \\
& \left(\begin{array}{ll}
1 & \gamma
\end{array}\right) c_{2 H}^{1} \leqslant\left[R^{H}\left(1 \quad z_{j}\right)+R^{L} z_{i j}+R^{L} z_{i j}\right] x \\
& =\left[\frac{1}{3} R^{H}+\frac{2}{3} R^{L}\right] x \\
& \left(\begin{array}{ll}
1 & \gamma
\end{array}\right) c_{2 H}^{2} \leqslant\left[R^{H}\left(1 \quad z_{j}\right)+R^{L} z_{i j}+R^{H} z_{i j}\right] x \\
& =\left[\frac{2}{3} R^{H}+\frac{1}{3} R^{L}\right] x \\
& \frac{1}{2}\left[\frac{1}{3} u\left(c_{2 L}^{1}\right)+\frac{2}{3} u\left(c_{2 L}^{2}\right)\right] \\
& +\frac{1}{2}\left[\frac{1}{3} u\left(c_{2 H}^{1}\right)+\frac{2}{3} u\left(c_{2 H}^{2}\right)\right] \geqslant u\left(c_{1 N}\right) ; \\
& x \geqslant 0 ; \quad y \geqslant 0 ; \quad z_{i}=z_{j}=\sum z_{i j} \text {; } \\
& c_{1 N} \geqslant 0 ; \quad c_{2 L}^{1} \geqslant 0 ; \quad c_{2 L}^{2} \geqslant 0 \text {; } \\
& c_{2 H}^{1} \geqslant 0 ; \quad c_{2 H}^{2} \geqslant 0 \text {; }
\end{aligned}
$$

where $c_{1 N}$ is the consumption of impatient consumers, $c_{2 L}^{1}\left(c_{2 H}^{1}\right)$ is the consumption of a patient depositor in a bad (good) bank in state 1 , and $c_{2 L}^{2}\left(c_{2 H}^{2}\right)$ is the consumption of a patient depositor in a bad (good) bank in states 2 and 3 . Eq. (17) is the expected utility to be maximized. The first row of the objective function is the expected consumption of type 1 agents and the expected consumption of type 2 agents in a bad bank. The second row represents the ex pected consumption of type 2 agents in a good bank. Eq. (18) is the period 0 constraint, where as before $x$ is the amount invested in storage, $y$ the amount invested in the illiquid asset and $z_{j}\left(z_{i}\right)$ are total interbank loans received from (given to) the neighbor banks. Eq. (19) is the first per iod constraint, and Eqs. (20) (23) are the second period ones, that will depend on the bank type and the state. Eq. (20) corresponds to the case where a depositor is at a bad bank that is in states 2 or 3 . The equation states that the consumption offered to patient depositors comes from the bank's project return $\left(R^{L} x\right)$, less its obligations with the banking system $\left(z_{j} R^{L} x\right)$ plus the funds received from its neighbors $\left(z_{i j} R^{H} x+z_{i j} R^{L} x\right)$. Eq. (21) corresponds to the case of a bad bank in state 1 . The bad bank is connected to two good banks. Similarly, Eq. (22) represents the contract of fered to patient depositors by a good bank that is in states 2 or 3, while Eq. (23) is the one offered by a good bank that is in state 1. Finally, Eq. (24) is the incentive compatibility constraint, which is expressed in expected terms, as the bank ignores both its return and that of its neighbors.

Although $c_{2 L}^{1}=c_{2 H}^{2}=c_{2}^{H}$ and $c_{2 L}^{2}=c_{2 H}^{1}=c_{2}^{L}$, we will treat them separately because they will have different con sequences in understanding the equilibria.

Let

$\bar{\Psi}=\left\{\bar{y}, \bar{x}, \overline{c_{1 N}},\left\{\overline{c_{2 i}^{s}}\right\}_{i}^{s} \quad 1,2, H\right\}$

be the optimal allocation offered to consumers depositors in an incomplete market structure of the neighboring case. It will be shown that in this case the first best allocation is not achievable. In the neighboring case, a depositor would find it optimal ex post to liquidate his deposits prematurely if the cost of obtaining information about their bank type in the first period is not too high, and provided other depositors are also acquiring information.

\subsubsection{Equilibria with liquidation and contagion in the neighboring case}

In this case, the possible equilibria are: a verification equilibrium with partial runs (with and without contagion), a verification equilibrium with total runs, a full run equilib rium and a no run equilibrium. In the last two equilibria, 
depositors do not verify the type of banks. They either withdraw from all banks or do not acquire information and do not withdraw.

As shown below, if condition (27) is satisfied, when depositors verify the type of banks, and they are in states 2 or 3 , it is always optimal to withdraw their deposits from bad banks. As a result, these banks have to liquidate their technology and their interbank loans, and will be able to pay a total amount of $\widehat{c_{1 N}}=\frac{x r+y+z_{i j} \overline{c_{N N}}}{1+z_{i j}}<\overline{c_{1 N}}$. ${ }^{7}$ On the other hand, the good bank will have to liquidate part of its long term asset in order to pay its interbank loans to the bad bank; however it would not enter into a bank run as long as $\widehat{c_{2 H}}=\frac{R^{H}(1-\lambda) x}{(1-\gamma)}>\overline{c_{1 N}}$, where $\lambda$ is the proportion of the investment in the long term asset that has to be liquidated in the first date in the good bank in order to be able to guarantee the promised consumption of $\overline{c_{1 N}}$. 8

Nevertheless, if second period consumption in the good bank is less than the promised one, that is, $\widehat{c_{2 H}}<\overline{c_{2}^{H}}$, the good bank is affected by contagion and is contractually bankrupt. This is the case of a verification equilibrium with partial bank runs and contagion. There is contagion because the expansion bank, even if it does not experience a run, it cannot pay its promised consumption to its late consumers. ${ }^{9}$

Another interesting case is the one of state 1, where a good bank is connected to two bad banks. In this state, depositors of good banks will generate a financial crisis due to the fundamentals of bad banks. As $\overline{c_{1 N}}>\overline{c_{2}^{L}}$ patient depositors have incentives to withdraw from the good banks (note that $\overline{c_{2 L}^{2}}=\overline{c_{2 H}^{1}}=\overline{c_{2}^{L}}$ ). On the other hand, if we define $\widehat{c_{2 L}}=\frac{x R^{L}(1-\lambda)}{(1-\gamma)}$, where as before $\lambda$ is the proportion of the investment in the long term asset that has to be liq uidated in the first date in the bad bank in order to be able to guarantee a consumption of $\overline{c_{1 N}}$, then as $\widehat{c_{2 L}}<\overline{c_{1 N}}$ then patient depositors will also withdraw from bad banks. The curiosity is that if patient depositors of good banks wait until $t=2$, they would receive less than depositors from bad banks. In this verification equilibrium with total bank runs all depositors receive $x r+y{ }^{10}$

The following propositions describe conditions for the existence of the different equilibria. All proofs are con tained in Appendix A.

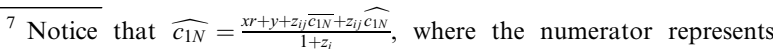
assets available given by the liquidation of the long term asset, the storage technology and liquidation of interbank loans with the good and the bad bank respectively. The liabilities of the bank are given by the denominator of the equation. Therefore, $\widehat{c_{1 N}}=\frac{x r+y+z_{i j} \overline{C_{1 N}}}{1+z_{i j}}$.

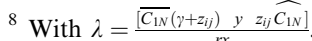

${ }^{9}$ This verification equilibrium with contagion will occur whenever $\lambda$ is greater than a value $\lambda^{*}$, for which $\widehat{c_{2 H}}=\overline{c_{2}^{H}}$, that is, $\lambda^{*}=\frac{1 / 3\left(R^{H} R^{L}\right)}{R^{H}}$. We thank the reviewer for pointing out this possibility.

10 This equilibrium takes place because of the linkages that good banks have established ex ante, due to the uncertainty about the future return. Finally, those linkages result in worse than being alone. This can be the case of depositors of banks in developed countries disapproving of their banks investing in other banks in underdeveloped countries.
}

Proposition 2. In states 2 and 3 , there is a verification equilibrium in which only bad banks are liquidated and good banks can either be affected or not by contagion, whereas in state 1 , all depositors will withdraw their deposits generating a financial crisis based on fundamentals.

The previous statement is going to be true when the fol lowing conditions are satisfied:

$$
\begin{aligned}
& \overline{c_{1 N}} \geqslant \overline{c_{2}^{L}}, \\
& \widehat{c_{2 H}} \geqslant \overline{c_{1 N}}, \\
& \frac{1}{3} u\left(\widehat{c_{2 H}} \quad \varepsilon\right)+\frac{1}{3} u(x r+y \quad \varepsilon)+\frac{1}{3} u\left(\widehat{c_{1 N}} \quad \varepsilon\right) \\
& \geqslant \frac{1}{3} u\left(\widehat{c_{2 H}}\right)+\frac{2}{3} u(0), \\
& \frac{1}{3} u\left(\widehat{c_{2 H}} \quad \varepsilon\right)+\frac{1}{3} u(x r+y \quad \varepsilon)+\frac{1}{3} u\left(\widehat{c_{1 N}} \quad \varepsilon\right) \geqslant, \\
& \frac{1}{3} u\left(\overline{c_{1 N}}\right)+\frac{1}{3} u\left(\widehat{c_{1 N}}\right)+\frac{1}{3} u(x r+y) .
\end{aligned}
$$

Eq. (27) indicates that the lowest possible consumption in the second period is smaller than consumption promised to impatient depositors. As a result it is optimal for patient depositors of bad banks in states 2 and 3 to withdraw their deposits in the first period (as well as for patient depositors of good banks in state 1). Eq. (28) guarantees that good banks will have enough resources to compensate patient depositors and avoid a bank run in states 2 and 3 .

Finally, Eqs. (29) and (30) state that if all other deposi tors are playing the verification equilibrium it is optimal to play it. ${ }^{11}$

Additionally, we still have the traditional equilibria, which are given in the following proposition:

Proposition 3. The no run and the full run are also Nash Equilibria of this game, if the following conditions are satisfied:

$$
\begin{aligned}
& \frac{1}{2} u\left(\overline{c_{2}^{H}}\right)+\frac{1}{2} u\left(\overline{c_{2}^{L}}\right) \geqslant u\left(\overline{c_{1 N}}\right), \\
& \frac{1}{2} u\left(\overline{c_{1 N}} \quad \varepsilon\right)+\frac{1}{2} u\left(\overline{c_{2}^{H}} \quad \varepsilon\right) \leqslant \frac{1}{2} u\left(\overline{c_{2}^{H}}\right)+\frac{1}{2} u\left(\overline{c_{2}^{L}}\right), \\
& \overline{c_{1 N}} \geqslant r .
\end{aligned}
$$

Eqs. (31) and (32) guarantee that an agent has no incentive to deviate in the no run equilibrium. Eq. (31) is the incen tive compatibility constraint while Eq. (32) guarantees that the benefit obtained by verifying and withdrawing when the outcome is inefficient, is lower than the expected utility achieved in the no run equilibrium. Finally, Eq. (33) guar antees the existence of the full run equilibrium. This condi tion says that if all depositors withdraw in the first period, neither good nor bad banks have enough resources to pay them the promised amount of $\overline{c_{1 N}}$.

\footnotetext{
$\overline{11}$ For a better description of these two equations, see Appendix A.
} 


\subsection{The island case}

In the island case, each bank is financially connected to just one bank in the system. As a consequence, we also have three possible states: One case where a good bank is connected to the other good and the bad bank to the other bad one, Fig. 4a and two cases where a good bank is linked to a bad bank, Fig. 4b and c. Each state is going to be equally probable.

In this case, banks will maintain total interbank loans of $z_{i}=\frac{1}{2}$ and so $z_{j}=\frac{1}{2}$.

Now, consumers depositors are going to solve the fol lowing problem:

$$
\begin{aligned}
& \underset{\left\{x, y, c_{1},\left\{c_{2 i}^{t}\right\}_{i=L, H}^{t=1,2}\right\}}{\operatorname{Max}} \quad \gamma u\left(c_{1 I}\right)+(1 \quad \gamma)\left\{\frac{1}{2}\left[\frac{2}{3} u\left(c_{2 L}^{B}\right)+\frac{1}{3} u\left(c_{2 L}^{A}\right)\right]\right. \\
& \left.+\frac{1}{2}\left[\frac{1}{3} u\left(c_{2 H}^{A}\right)+\frac{2}{3} u\left(c_{2 H}^{B}\right)\right]\right\} \\
& \text { subject to } x+y \quad z_{i}+z_{j} \leqslant 1 \text {; } \\
& \gamma c_{1 I} \leqslant y \text {; } \\
& \left.(1 \quad \gamma) c_{2 L}^{A} \leqslant\left[\begin{array}{ll}
R^{L}(1 & z_{j}
\end{array}\right)+R^{L} z_{i}\right] x=R^{L} x ; \\
& \left.\left(\begin{array}{ll}
1 & \gamma
\end{array}\right) c_{2 L}^{B} \leqslant\left[\begin{array}{ll}
R^{L}(1 & z_{j}
\end{array}\right)+R^{H} z_{i}\right] x \\
& =\left[\frac{1}{2} R^{L}+\frac{1}{2} R^{H}\right] x \\
& \left(\begin{array}{ll}
1 & \gamma
\end{array}\right) c_{2 H}^{A} \leqslant\left[R^{H}\left(1 \quad z_{j}\right)+R^{H} z_{i}\right] x \\
& =R^{H} x \\
& \left(\begin{array}{ll}
1 & \gamma
\end{array}\right) c_{2 H}^{B} \leqslant\left[R^{H}\left(1 \quad z_{j}\right)+R^{L} z_{i}\right] x \\
& =\left[\frac{1}{2} R^{H}+\frac{1}{2} R^{L}\right] x \text {; } \\
& \frac{1}{2}\left[\frac{2}{3} u\left(c_{2 L}^{B}\right)+\frac{1}{3} u\left(c_{2 L}^{A}\right)\right] \\
& +\frac{1}{2}\left[\frac{1}{3} u\left(c_{2 H}^{A}\right)+\frac{2}{3} u\left(c_{2 H}^{B}\right)\right] \geqslant u\left(c_{1 I}\right) ; \\
& x \geqslant 0 ; \quad y \geqslant 0 ; \quad c_{1 I} \geqslant 0 ; \quad c_{2 L}^{A} \geqslant 0 ; \\
& c_{2 L}^{B} \geqslant 0 ; \quad c_{2 H}^{A} \geqslant 0 ; \quad c_{2 H}^{B} \geqslant 0 ;
\end{aligned}
$$

where $c_{1 I}$ is the consumption of an impatient consumer, $c_{2 L}^{A}\left(c_{2 H}^{A}\right)$ is the consumption of a patient depositor of a bad (good) bank in state $\mathrm{I}$, and $c_{2 L}^{B}\left(c_{2 H}^{B}\right)$ is the consump tion of a patient depositor of a bad (good) bank in states II and III. Eq. (34) is the expected utility to be maximized. The first row of the objective function is the consumption of type 1 agents and the expected consumption of type 2 agents in a bad bank. The second row represents the ex pected consumption of type 2 agents in a good bank. Eq. (35) is the period 0 constraint, where $x$ is the amount in vested in storage, $y$ the amount invested in the illiquid asset and $z_{j}\left(z_{i}\right)$ are total interbank loans received from (given to) the partner bank. Eq. (36) is the first period constraint, and Eqs. (37) (40) are the second period ones, that will de pend on the bank type and the state. Eq. (37) corresponds to the case of a bad bank in state I. It states that the con sumption of patient depositors comes from the banks's re turn $\left(R^{L} x\right)$, less its obligation with the system $\left(z_{j} R^{L} x\right)$, and from the return obtained from the other bank $\left(z_{i j} R^{L} x\right)$. Eq. (38) corresponds to the case of a bad bank in states II and III. Similarly, Eq. (39) refers to the case of a good bank in state I and Eq. (40) represents the case of a good bank in states II and III. Finally, Eq. (41) is the incentive compatibility constraint, which is expressed in expected terms, as the bank ignores both its return and that of its neighbors.

Let

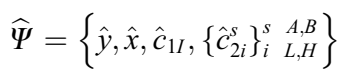

be the optimal allocation offered to consumers depositors in an incomplete market structure of the island case. It will be shown that the equilibrium achieved in the island case is worse than the first best allocation achieved in the complete market structure and also worse than the second best of fered in the neighboring case.

\subsubsection{Equilibria with liquidation in the island case}

In the island case, three different equilibria are possible: a verification equilibrium (with partial bank runs), a full run equilibrium and a no run equilibrium.

$\begin{array}{ccccccccccccccc} & G_{1} & B_{2} & B_{3} & G_{4} & & G_{1} & B_{2} & B_{3} & G_{4} & & G_{1} & B_{2} & B_{3} & G_{4} \\ G_{1} & 0 & 0 & 0 & 1 & G_{1} & 0 & 0 & 1 & 0 & G_{1} & 0 & 1 & 0 & 0 \\ B_{2} & 0 & 0 & 1 & 0 & B_{2} & 0 & 0 & 0 & 1 & B_{2} & 1 & 0 & 0 & 0 \\ B_{3} & 0 & 1 & 0 & 0 & B_{3} & 1 & 0 & 0 & 0 & B_{3} & 0 & 0 & 0 & 1 \\ G_{4} & 1 & 0 & 0 & 0 & G_{4} & 0 & 1 & 0 & 0 & G_{4} & 0 & 0 & 1 & 0\end{array}$

(a) State I (b) State II (c) State III

Fig. 4. States of nature in the island case. 
In the verification equilibrium, depositors verify the type of banks, and withdraw from bad ones. As a result, in state I, impatient and patient depositors of bad banks will receive $x r+y$. Impatient depositors of good banks will receive $\widehat{c}_{1 I}$, while patient depositors of good banks will receive $\widehat{c}_{2 H}^{A}$. In the other two cases (states II and III), impa tient depositors will receive $\hat{c}_{1 I}$, while patient depositors will receive $\hat{c}_{2 H}^{B}=\hat{c}_{2 L}^{B}=\hat{c}_{2}^{T}$.

The difference with the verification equilibrium of the neighboring case is that NO contagion occurs.

The following propositions describe conditions for the existence of the different equilibria. All proofs are con tained in Appendix A.

Proposition 4. In state I of the Island case, there is a verification equilibrium where depositors of bad banks withdraw their deposit in the first period due to fundamentals and depositors of good banks wait until $t=2$ and obtain the maximum return, if the following conditions are satisfied:

$$
\begin{aligned}
& \hat{c}_{1 I} \geqslant \hat{c}_{2 L}^{A}, \\
& \frac{2}{3} u\left(\begin{array}{lll}
\hat{c}_{2}^{T} & \varepsilon
\end{array}\right)+\frac{1}{6}\left(\begin{array}{ll}
x r+y & \varepsilon
\end{array}\right)+\frac{1}{6}\left(\begin{array}{ll}
\hat{c}_{2 H}^{A} & \varepsilon
\end{array}\right) \\
& \geqslant \frac{2}{3} u\left(\hat{c}_{2}^{T}\right)+\frac{1}{6} u(0)+\frac{1}{6} u\left(\hat{c}_{2 H}^{A}\right), \\
& \frac{2}{3} u\left(\begin{array}{ll}
\hat{c}_{2}^{T} & \varepsilon
\end{array}\right)+\frac{1}{6} u(x r+y \quad \varepsilon)+\frac{1}{6} u\left(\begin{array}{ll}
\hat{c}_{2 H}^{A} & \varepsilon
\end{array}\right) \\
& \geqslant \frac{5}{6} u\left(\hat{c}_{1 I}\right)+\frac{1}{6} u(x r+y) \text {. }
\end{aligned}
$$

Eq. (43) guarantees that it is optimal for depositors of bad banks to withdraw their deposits in the first period. Eqs. (44) and (45) ensure that if all agents play the verification equilibrium, it is not optimal for any agent to deviate.

As in the neighboring case, we have the traditional equi libria, which are summarized in the proposition below:

Proposition 5. In the island case, the no run and the full run are still Nash Equilibria, if the following conditions are satisfied:

$$
\begin{aligned}
& \frac{2}{3} u\left(\hat{c}_{2}^{T}\right)+\frac{1}{6} u\left(\hat{c}_{2 L}^{A}\right)+\frac{1}{6} u\left(\hat{c}_{2 H}^{A}\right) \geqslant u\left(\hat{c}_{1 I}\right), \\
& \frac{2}{3} u\left(\hat{c}_{2}^{T}\right)+\frac{1}{6} u\left(\hat{c}_{2 L}^{A}\right)+\frac{1}{6} u\left(\hat{c}_{2 H}^{A}\right) \\
& \quad \geqslant \frac{2}{3} u\left(\begin{array}{ll}
\hat{c}_{2}^{T} & \varepsilon)+\frac{1}{6} u\left(\begin{array}{ll}
\hat{c}_{1 I} & \varepsilon
\end{array}\right)+\frac{1}{6} u\left(\begin{array}{ll}
\hat{c}_{2 H}^{A} & \varepsilon
\end{array}\right), \\
\hat{c}_{1 I} \geqslant r .
\end{array}\right.
\end{aligned}
$$

Eqs. (46) and (47) guarantee that an agent has no incen tive to deviate in the no run equilibrium. Eq. (46) is the incentive compatibility constraint while Eq. (47) guaran tees that the benefit obtained by verifying and withdraw ing when the outcome is inefficient, is lower that the expected utility achieved in the no run equilibrium. Final ly, Eq. (48) guarantees the existence of the full run equi librium. This is the condition that guarantees that if all depositors withdraw in the first period, neither good nor bad banks have enough resources to pay them the prom ised amount of $\widehat{c}_{1 I}$.

\section{The role for a Central Bank}

As a consequence of the rapid spread of the Asian crisis of 19971998 to the global financial markets, the IMF introduced the Contingent Credit Lines (CCL) in 1999. The idea of the CCL was to provide a precautionary line of defense for members with sound policies, who were not at risk of an external payments crisis of their own mak ing, but were vulnerable to contagion effects from capital account crisis in other countries. The package allowed those countries that met certain eligibility criteria, to draw on a pre specified amount of resources if hit by a financial crisis due to factors outside of the member's control.

We have seen in the previous sections that in the pres ence of an incomplete market structure of the neighboring case, banks are subject to the risk of contagion and finan cial crises. In this section, we will show that there is a role for a Central Bank to complete markets. In our setting, the Central Bank will require reserves from banks at date 0 and will redistribute such reserves into the banking system in the form of credit lines to banks. With the Central Bank, the first best allocation is achieved when the financial sys tem is incomplete. ${ }^{12}$

The World Bank and other international institutions like the IMF reallocate resources during financial crises. In what follows, we show that such behavior can be socially optimal. The Central Bank is going to require reserves of $\left(T_{i}=\frac{1}{4}\right)$ from each bank which is going to main tain in the system $\left(T_{j}=\frac{1}{4}\right)$ in order to allow banks to max imize depositors' expected utility.

These reserves work in the same way as interbank loans, banks will have to pay an amount to the Central Bank, that is contingent on the resources available in the second period, that is, $T_{j}\left[\widetilde{R}_{i} \quad z_{j} \widetilde{R}_{i}+z_{i} \widetilde{R}_{j}\right] x$ (where $\widetilde{R}_{i}$ is the expected return from our technology, and $\widetilde{R}_{j}$ is the expected return from our neighbor banks). Additionally, banks will receive a payment in the form of a "Contingent Credit Line" from the Central Bank that will restore the social optimal allocation. The intuition says that the Cen tral Bank will complete markets, and so bad banks that are in states 2 and 3 and good banks in state 1 will receive $T_{i} R^{H} x$, which is more than what they pay $\left(T_{i} R^{H} x>T_{j}\right.$ $\left.\left[R^{L}\left(1 \quad z_{j}\right)+R^{H} z_{i j}+R^{L} z_{i j}\right] x\right)$. On the other hand, good banks that are in states 2 and 3 , and bad banks of state 1 will receive $T_{i} R^{L} x$, which is less than what they pay $\left(T_{i} R^{L} x<T_{j}\left[R^{L}\left(1 \quad z_{j}\right)+R^{H} z_{i j}+R^{H} z_{i j}\right] x\right) .{ }^{13}$

\footnotetext{
${ }^{12}$ It should be noted that in the island case, there is no role for a Central Bank, as in the bad state of nature there is no contagion and that is why bad banks are penalized and good banks are not affected.

${ }^{13}$ Recall that patient depositors of bad banks in states 2 and 3 obtained the same consumption as patient depositors of good banks in state 1 $\left(c_{2 L}^{2}=c_{2 H}^{1}=c_{2}^{L}\right)$. Similarly, patient depositors of good banks in states 2 and 3 received the same as those of bad banks in state $1\left(c_{2 L}^{1}=c_{2 H}^{2}=c_{2}^{H}\right)$.
} 
The problem to be maximized, when a Central Bank is introduced, is as follows:

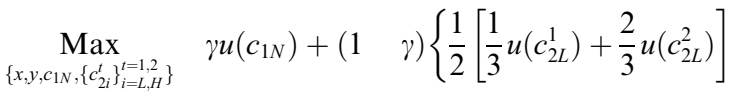

$$
\begin{aligned}
& \left.+\frac{1}{2}\left[\frac{1}{3} u\left(c_{2 H}^{1}\right)+\frac{2}{3} u\left(c_{2 H}^{2}\right)\right]\right\} \\
& \text { subject to } \quad x+y \quad z_{i}+z_{j} \quad T_{i}+T_{j} \leqslant 1 \text {; } \\
& \gamma c_{1 N} \leqslant y \\
& \left(\begin{array}{ll}
1 & \gamma) c_{2 L}^{2} \leqslant\left\{\left[\begin{array}{ll}
R^{L}(1 & z_{j}
\end{array}\right)+R^{H} z_{i j}+R^{L} z_{i j}\right.
\end{array}\right] \\
& \left.\left.\times\left(\begin{array}{ll}
1 & T_{j}
\end{array}\right)+T_{i} R^{H}\right]\right\} x ; \\
& \left(\begin{array}{ll}
1 & \gamma) c_{2 L}^{1} \leqslant\left\{\left[\begin{array}{ll}
R^{L}(1 & z_{j}
\end{array}\right)+R^{H} z_{i j}+R^{H} z_{i j}\right.
\end{array}\right] \\
& \left.\times\left(\begin{array}{ll}
1 & T_{j}
\end{array}\right)+T_{i} R^{L}\right\} x ; \\
& \left(\begin{array}{ll}
1 & \gamma
\end{array}\right) c_{2 H}^{1} \leqslant\left\{\left[R^{H}\left(\begin{array}{ll}
1 & z_{j}
\end{array}\right)+R^{L} z_{i j}+R^{L} z_{i j}\right]\right. \\
& \left.\left.\times\left(\begin{array}{ll}
1 & T_{j}
\end{array}\right)+T_{i} R^{H}\right]\right\} x ; \\
& \left.\left(\begin{array}{ll}
1 & \gamma) c_{2 H}^{2} \leqslant\left\{\left[R ^ { H } \left(1 \quad z_{j}\right.\right.\right.
\end{array}\right)+R^{L} z_{i j}+R^{H} z_{i j}\right] \\
& \left.\times\left(\begin{array}{ll}
1 & T_{j}
\end{array}\right)+T_{i} R^{L}\right\} x ; \\
& \frac{1}{2}\left[\frac{1}{3} u\left(c_{2 L}^{1}\right)+\frac{2}{3} u\left(c_{2 L}^{2}\right)\right] \\
& +\frac{1}{2}\left[\frac{1}{3} u\left(c_{2 H}^{1}\right)+\frac{2}{3} u\left(c_{2 H}^{2}\right)\right] \geqslant u\left(c_{1 N}\right) ; \\
& x \geqslant 0 ; \quad y \geqslant 0 ; \quad c_{1 N} \geqslant 0 ; \quad c_{2 L}^{1} \geqslant 0 \\
& c_{2 L}^{2} \geqslant 0 ; \quad c_{2 H}^{1} \geqslant 0 ; \quad c_{2 H}^{2} \geqslant 0 ; \\
& z_{i}=\sum z_{i j} ; \quad T_{i}=T_{j}=\frac{1}{4} \text {. }
\end{aligned}
$$

Eq. (49) is equal to Eq. (17), the objective function in the neighboring case. Eq. (50) is the budget constraint, that is equal to Eq. (18) of the neighboring case, except that it considers reserves required and received from the Central Bank. Eq. ( 51) is the first period constraint which is also identical to Eq. (19) in the neighboring case and finally, Eqs. (52) (55) are the second period constraints, which take into account amounts paid to and received from the Central Bank, respectively.

Eq. (52) corresponds to the case where a depositor is at a bad bank that is in states 2 or 3 . Recall that the bad bank is connected to one good bank and to one bad one. In this case, the bank pays a proportion $T_{j} x$ of the resources avail

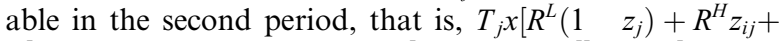

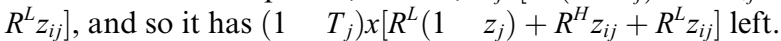
On the other hand, it receives the amount $T_{i} x R^{H}$ as a con tingent credit line. The rest of the equations have a similar interpretation. Eq. (53) corresponds to the case of a bad bank in state 1. Eq. (54) represents the contract offered to patient depositors by a good bank that is in states 2 or 3, while Eq. (55) is the one offered by a good bank that is in state 1. Finally, Eq. (56) is the incentive compatibility constraint, which is identical to Eq. (24) of the neighboring case.

Under these conditions, it is easy to show that the first best allocation is achieved. Notice that $c_{2 L}^{2}=c_{2 H}^{1}=$ $\frac{\left\{\left[R^{L}\left(1-z_{j}\right)+R^{H} z_{i j}+R^{L} L_{i j}\right]\left(1-T_{j}\right)+T_{i} R^{H}\right\} x}{1-\gamma}=\frac{\bar{R} x}{1-\gamma}$. Similarly, $c_{2 L}^{1}=c_{2 H}^{2}=$ $\frac{\left\{\left[R^{L}\left(1-z_{j}\right)+R^{H} z_{i j}+R^{H} z_{i j}\right]\left(1-T_{j}\right)+T_{i} R^{L}\right\} x}{1-\gamma}=\frac{\bar{R} x}{1-\gamma}$, and so the problem is reduced to the social planner's problem analyzed in Section 3.

The idea is that the Central Bank guarantees the optimal level of risk sharing and therefore avoids contagion and financial crises. Those international institutions work as international market insurers (or market completers), since it is frequent to observe that although some financial sys tems are not connected due to political or economic rea sons, they can be indirectly connected through those international institutions in order to avoid financial crises and increase social welfare.

It should be noted that in practice the behavior of the IMF is affected by the fear of moral hazard problems. This implies that the CCL would be extended in state 1 , or in states 2 and 3 , but when there is contagion $\left(\lambda>\lambda^{*}\right)$. In our setting moral hazard is absent and so it is welfare supe rior to avoid information gathering and to prevent every financial crisis equilibria.

\section{Numerical example}

A numerical example nicely illustrates the results pre sented in this paper. In the example that follows, preferences and parameters values are displayed in Table 1; while the results from the optimization problem appear in Table 2 , columns 14 , for the complete market structure, the neigh boring case, the island case and autarky, respectively. For these values, all the conditions for the existence of the differ ent equilibria in the neighboring case are satisfied for any $\varepsilon \in(0.058 ; 0.06)$. Similarly, all the conditions for the exis tence of the different equilibria in the island cased are satis fied for any $\varepsilon \in(0.126 ; 0.151)$. Note that for these values verification is never socially optimal, as $\varepsilon^{*}=0.023$.

Additionally, we obtain that in states 2 and 3 of the neigh boring case there is a verification equilibrium with partial bank runs and contagion. There is contagion because the expansion bank, even if it does not experience a run, it cannot pay its promised consumption to its late consumers. Recall that this equilibrium takes place whenever the proportion of the long term asset that is liquidated at $t=1(\lambda)$, is greater than a threshold level of $\lambda^{*}$, which guarantees that second period consumption is equal to the promised one. In the example, $\lambda=0.25>\lambda^{*}=0.235$, and so we have a verifica tion equilibrium with partial runs and contagion (Table 1).

Obviously, the highest expected utility corresponds to the complete market structure where the first best is achieved fol lowed by the neighboring and the island cases respectively. The occurrence of contagion does not impede that the alloca tion reached in the neighboring case is higher than that of the island case. Therefore, contagion and crisis are the conse quences of the higher expected utility that can be reached when a complete market structure is not a possible one.

\section{Conclusion}

The paper incorporates costly voluntary acquisition of information à la Nikitin and Smith (2007), in a framework 
Table 1

Values of the parameters

\begin{tabular}{llllllllll}
\hline$u\left(c_{1}\right)$ & $u\left(c_{2}\right)$ & $R^{H}$ & $R^{L}$ & $r$ & $\gamma$ & $\bar{R}$ & $k$ & $\lambda^{*}$ & $\varepsilon^{*}$ \\
\hline $\operatorname{Ln}\left(c_{1}+k\right)$ & $\operatorname{Ln}\left(c_{2}+k\right)$ & 1.7 & 0.5 & 0.5 & 0.5 & 1.1 & 0.000001 & 0.25 & 0.235 \\
\hline
\end{tabular}

Table 2

Numerical example

\begin{tabular}{llll}
\hline $\begin{array}{l}\text { Complete market } \\
\text { structure }\end{array}$ & $\begin{array}{l}\text { Neighboring } \\
\text { case }\end{array}$ & Island case & Autarky \\
\hline$x=0.5$ & $x=0.5$ & $x=0.5$ & $x=0.514$ \\
$y=0.5$ & $y=0.5$ & $y=0.5$ & $y=0.486$ \\
$c_{1}=1$ & $c_{1 N}=1$ & $c_{1 I}=1$ & $c_{1 I M P}=0.973$ \\
$c_{2}=1.1$ & $c_{2 L}^{2}=0.9$ & $c_{2 L}^{A}=0.5$ & $c_{2 H}=1.7458$ \\
$E U=0.0476$ & $c_{2 L}^{1}=1.3$ & $c_{2 L}^{B}=1.1$ & $c_{2 L}=0.513$ \\
& $c_{2 H}^{1}=0.9$ & $c_{2 H}^{A}=1.7$ & $E U=0.041$ \\
& $c_{2 H}^{2}=1.3$ & $c_{2 H}^{B}=1.1$ & \\
& $E U=0.039$ & $E U=0.0182$ & \\
& $(x r+y)=0.75$ & $(x r+y)=0.75$ & \\
& $\widehat{c_{1 N}}=08125$ & & \\
& $\widehat{c_{2 H}}=1.275$ & & \\
& $\widehat{c_{2 L}}=0.375$ & & \\
& & & \\
\hline
\end{tabular}

similar to Allen and Gale (2000). This allows us to model the relationship between shocks to fundamentals and con tagion, without relying on any unexpected shock to model contagion.

In the paper, depositors can modify their behavior due to the use of costly information. When the system is at rest, individuals do not find it optimal to gather information and so our model explains why there are periods in which individuals do not modify their expectations on banks. However, if for any reason they decide to invest in informa tion gathering they would penalize those states of nature in which banks establish inefficient links. This would cause the liquidation of bad projects, but it might also generate contagion and financial crises when financial linkages are very inaccurate.

In the neighboring case, two possible equilibria with contagion, due to fundamentals, are possible. In the first one, bad banks fail and good banks are affected by conta gion. Even though good banks are not affected by bank runs and can meet their obligations with impatient depos itors, the malfunctioning of the interbank payment system obliges them to liquidate part of their long term technol ogy. As a result, good banks go bankrupt in the second period. In the second equilibrium, depositors in good banks withdraw their deposits generating a collapse of the entire banking system. These equilibria have very low probability but can explain the occurrence of some interna tional financial crises.

From our analysis, it can be concluded that a complete market structure is resilient to shocks in fundamentals. For the case of incomplete market structures, we find that the more incomplete the banking structure is, read the island case, the less vulnerable to contagion it is. Nevertheless, depositors prefer the neighboring case to the island case.
In this respect our results are similar to those of Castiglio nesi and Brusco (2007). They find that banks establish links and accept the risk of contagion only when the risk is not too big.

Finally, we analyze the existence of international institu tions like the World Bank and the IMF. In our model, those institutions appear as an optimal solution when polit ical restrictions impede perfect capital flows. We present the importance of some mechanisms like the Contingent Credit Line (CCL) of the IMF to eradicate crises and pre vent contagion.

It should be noted that in our setting moral hazard is absent and so it is welfare superior to avoid information gathering and to prevent every financial crisis equilibrium. An avenue for future research would be to analyze the opti mality of those institutions in the presence of moral hazard or aggregate uncertainty.

\section{Acknowledgements}

The authors would like to thank Sandro Brusco, Xavier Mateos Planas, Hugo Benitez Silva, seminar participants at SUNY at Stony Brook, Universidad Carlos III, XXXI Simposio de Analisis Económico and XV Foro de Finan zas, as well as two anonymous referees for their helpful comments in an earlier version of this paper. The advice of Georgio Szegö during the reviewing process is also acknowledged. This research is partially funded by the Spanish Ministry of Education and Culture, projects SEJ2004 01688 and SEJ2007 67448/ECON.

\section{Appendix A}

First,considerconditionsfortheexistenceofequilibriainthe Incomplete MarketStructure of the neighboring case.

Proof of Proposition 2. In states 2 and 3, depositors of bad banks receive $\overline{c_{2}^{L}}$, which is smaller than $\overline{c_{1 N}}$ (Eq. (27)). If depositors acquire information and find out that they are in those states, they will withdraw their deposits in the first year. Eq. (28) guarantees that patient depositors of good banks will still find it beneficial to wait until $t=2$, and so there are no bank runs. On the other hand, if depositors gather information and realize that they are in state 1, they would behave as impatient consumers and will generate a financial crisis. Eq. (27) ensures that patient depositors of good banks would prefer to behave as impatient depositors (note that $\overline{c_{2 H}^{1}}=\overline{c_{2 L}^{2}}=\overline{c_{2}^{L}}$ ), but since bad banks do not have enough resources to compensate its interbank loans, patient depositors of bad banks will also withdraw their deposits generating a global financial crisis. 
Finally, Eqs. (29) and (30) ensure that if all other agents are playing the verification equilibrium, it is optimal to play it. Eq. (29) states that the expected utility an agent achieves by acquiring information and withdrawing from inefficient banks is higher than that obtained by doing nothing, and waiting until the second year. Eq. (30) ensures that an indiscriminate withdrawal is neither optimal.

Proof of Proposition 3. Eqs. (31) and (32) ensure that patient depositors do not have an incentive to deviate in the no-run equilibrium. Eq. (31) is the incentive compatibility constraint that results from:

$\frac{1}{2}\left[\frac{1}{3} u\left(\overline{c_{2 L}^{1}}\right)+\frac{2}{3} u\left(\overline{c_{2 L}^{2}}\right)\right]+\frac{1}{2}\left[\frac{1}{3} u\left(\overline{c_{2 H}^{1}}\right)+\frac{2}{3} u\left(\overline{c_{2 H}^{2}}\right)\right] \geqslant u\left(\overline{c_{1 N}}\right)$

where the left hand side is the expected utility of patient depositors and the right hand side is the expected utility of impatient ones. We obtain the result of the formula by making use of the fact that $\overline{c_{2 L}^{1}}=\overline{c_{2 H}^{2}}=\overline{c_{2}^{H}}$ and $\overline{c_{2 L}^{2}}=$ $\overline{c_{2 H}^{1}}=\overline{c_{2}^{L}}$.

Eq. (32) guarantees that the expected utility of patient depositors is greater than the expected utility obtained by the policy of acquiring information and withdrawing when the consumption offered for being patient is low.

Finally, Eq. (33) guarantees the existence of the full-run equilibrium. This is the condition that guarantees that if all depositors withdraw in the first period, neither good nor bad banks have enough resources to pay them the promised amount of $\overline{c_{1 N}}$.

Second, consider conditions for the existence of equilibria in the Incomplete Market Structure of the island case.

Proof of Proposition 4. In state I, if depositors from bad banks obtain information and realize that they are in that state, they will receive $\widehat{c}_{2 L}^{A}$ which is less than $\widehat{c}_{1 I}$, so they will behave as impatient depositors. As a consequence, bad banks are liquidated and pay $x r+y$ to all depositors. Good banks are not affected by the shock since they do not have links with bad banks, and so they will pay depositors as promised in the demand deposit contract.

Eqs. (44) and (45) guarantee that if all agents play the verification equilibrium, it is not optimal for any agent to deviate. Eq. (44) states that the expected utility an agent achieves by acquiring information and withdrawing from inefficient banks is higher than that obtained by doing nothing, and waiting until the second year. Eq. (45) ensures that an indiscriminate withdrawal is neither optimal.
Proof of Proposition 5. Eqs. (46) and (47) guarantee that if all other agents do not gather information (play the no-run equilibrium) it is not optimal for any agent to deviate.

Eq. (46) is the incentive compatibility constraint that results from:

$\frac{1}{2}\left[\frac{2}{3} u\left(\widehat{c}_{2 L}^{B}\right)+\frac{1}{3} u\left(\widehat{c}_{2 L}^{A}\right)\right]+\frac{1}{2}\left[\frac{1}{3} u\left(\widehat{c}_{2 H}^{A}\right)+\frac{2}{3} u\left(\widehat{c}_{2 H}^{B}\right)\right] \geqslant u\left(\widehat{c}_{1 I}\right)$,

where the left hand side is the expected utility of patient depositors and the right hand side is the expected utility of impatient ones. We make use of the fact that $\hat{c}_{2 L}^{B}=$ $\hat{c}_{2 H}^{B}=\hat{c}_{2}^{T}$.

Eq. (47) guarantees that the expected utility of patient depositors is greater than the expected utility obtained by the policy of acquiring information and withdrawing when the consumption offered for being patient is low.

Finally, Eq. (48) guarantees the existence of the full-run equilibrium. This is the condition that guarantees that if all depositors withdraw in the first period, neither good nor bad banks have enough resources to pay them the promised amount of $\widehat{c}_{1 N}$.

\section{References}

Aghion, P., Bolton, P., Dewatripont, M., 2000. Contagious bank failures in a free banking system. European Economic Review 44, 713718.

Allen, F., Gale, D., 1998. Optimal financial crises. Journal of Finance 53, 12451284.

Allen, F., Gale, D., 2000. Financial contagion. Journal of Political Economy 108, 133.

Beim, D., Calomiris, C., 2001. Emerging Financial Markets. McGraw Hill International Edition.

Castiglionesi, F., 2007. Financial contagion and the role of the Central Bank. Journal of Banking and Finance 31 (1), 81101.

Castiglionesi, F., Brusco, S., 2007. Liquidity coinsurance, moral hazard and financial contagion. Journal of Finance 62 (5), 22752302.

Freixas, X., Parigi, B., 1998. Contagion and efficiency in gross and net interbank payment systems. Journal of Financial Intermediation (7), 331.

Freixas, X., Parigi, B., Rochet, J.C., 2000. Systemic risk, interbank relations, and liquidity provision by the Central Bank. Journal of Money, Credit, and Banking 33 (2), 611638.

Leitner, Y., 2005. Financial Networks: Contagion, Commitment, and Private Sector Bailouts. Journal of Finance 60 (6), 29252953.

Lindgren, C., Garcia, G., Saal, M., 1996. Bank Soundness and Macro economic Policy. International Monetary Fund.

Nikitin, M., Smith, R.T., 2007. Information acquisition, coordination, and fundamentals in a financial crisis. Journal of Banking and Finance, in press, doi:10.1016/j.jbankfin.2007.04.031.

Rochet, J.C., Tirole, J., 1996. Interbank lending and systemic risk. Journal of Money, Credit and Banking 28, 733762.

Saez, L., Shi, X., 2004. Liquidity pools, risk sharing, and financial contagion. Journal of Financial Services Research 25 (1), 523. 